\title{
Ceilometer lidar comparison: backscatter coefficient retrieval and signal-to-noise ratio determination
}

\author{
B. Heese ${ }^{1}$, H. Flentje ${ }^{2}$, D. Althausen ${ }^{1}$, A. Ansmann ${ }^{1}$, and S. Frey ${ }^{3}$ \\ ${ }^{1}$ Leibniz Institute for Tropospheric Research, Permoserstr. 15, 04318 Leipzig, Germany \\ ${ }^{2}$ German Meteorological Service, Meteorological Observatory, Hohenpeissenberg, Germany \\ ${ }^{3}$ JENOPTIK, ESW GmbH, Jena, Germany \\ Received: 29 July 2010 - Published in Atmos. Meas. Tech. Discuss.: 30 August 2010 \\ Revised: 8 December 2010 - Accepted: 13 December 2010 - Published: 20 December 2010
}

\begin{abstract}
The potential of a new generation of ceilometer instruments for aerosol monitoring has been studied in the Ceilometer Lidar Comparison (CLIC) study. The used ceilometer was developed by Jenoptik, Germany, and is designed to find both thin cirrus clouds at tropopause level and aerosol layers at close ranges during day and night-time. The comparison study was performed to determine up to which altitude the ceilometers are capable to deliver particle backscatter coefficient profiles. For this, the derived ceilometer profiles are compared to simultaneously measured lidar profiles at the same wavelength. The lidar used for the comparison was the multi-wavelengths Raman lidar Polly ${ }^{\mathrm{XT}}$. To demonstrate the capabilities and limits of ceilometers for the derivation of particle backscatter coefficient profiles from their measurements two examples of the comparison results are shown. Two cases, a daytime case with high background noise and a less noisy night-time case, are chosen. In both cases the ceilometer profiles compare well with the lidar profiles in atmospheric structures like aerosol layers or the boundary layer top height. However, the determination of the correct magnitude of the particle backscatter coefficient needs a calibration of the ceilometer data with an independent measurement of the aerosol optical depth by a sun photometer. To characterizes the ceilometers signal performance with increasing altitude a comprehensive signal-to-noise ratio study was performed. During daytime the signal-to-noise ratio is higher than 1 up to $4-5 \mathrm{~km}$ depending on the aerosol content. In our night-time case the SNR is higher than 1 even up to $8.5 \mathrm{~km}$, so that also aerosol layers in the upper troposphere had been detected by the ceilometer.
\end{abstract}

Correspondence to: $\mathrm{B}$. Heese (birgit.heese@ tropos.de)

\section{Introduction}

The German Meteorological Service (DWD) is presently setting up a ceilometer network. About two-thirds of 60 planned instruments are already in operation. The network uses the Jenoptik ceilometer of type CHM15k. This ceilometer has a narrow line width laser and an avalanche photodiode for the signal detection in photon counting mode. Due to these specifications these ceilometers have the potential to explore the vertical aerosol distribution. The primary intention of the network was operational synoptic cloud base observations. Besides cloud base range finding aerosol measurements by ceilometers have been studied before, mainly using instruments from Vaisälä (e.g., Sundström et al., 2000; McKendry et al., 2009). These ceilometers use a comparatively broad line width laser which complicates the daylight background suppression. Markowicz et al. (2007) found that the Vaisälä CT25K aerosol profiling is mostly limited to the boundary layer, but it is capable of detecting particles in the lower atmosphere such as mineral dust between 1 and $3 \mathrm{~km}$. A study by Martucci et al. (2010) is comparing Vaisälä CL31 and the Jenoptik CHM15k cloud base height detection. In this study they notice that the CHM15k return shows a higher sensitivity to the aerosol measurements (i.e., more features are detected below the cloud base). Another study on the retrieval of the boundary layer aerosol by the Jenoptik ceilometer was presented by Stachlewska and Markowicz (2010). Here, a self-calibrating method using the instrumental constant is presented that allows an independent calibration of the obtained backscatter coefficient profile.

In our study we want to investigate the ability of the Jenoptik ceilometer to quantitatively determine the vertical aerosol profile. In the frame of the ceilometer lidar comparison (CLIC) study the retrieval of the particle backscatter coefficient profile from the ceilometer data was investigated

Published by Copernicus Publications on behalf of the European Geosciences Union. 
and compared to aerosol profiles independently assessed from other instruments. One of the DWD ceilometers is located at the regional DWD weather center in LeipzigHolzhausen which lies at about $2 \mathrm{~km}$ distance from the Leibniz Institute for Tropospheric Research (IfT). As will be shown by the compared profiles, the horizontal variability of the aerosol is small enough to allow a representative comparison. For the study daily ceilometer data from January to June 2009 were available from the instrument placed in Leipzig-Holzhausen. The number of comparison cases was generally limited since cloud free conditions and simultaneously measured profiles from one of IfTs multi-wavelengths aerosol lidars, the portable Raman lidar system Polly ${ }^{\mathrm{XT}}$ were needed. The normal measurement schedule of the lidar is daily two times three hours: from midnight to 03:00 UTC and from noon to 15:00 UTC. Clear sky conditions that lasted for some hours were indeed not numerous during the lidar observation times and thus in total 10 cases were chosen for the study. An example of a daytime measurement from these comparisons will be shown.

Another opportunity for the ceilometer lidar comparison occurred in May 2009 when the European Aerosol Research Lidar Network (EARLINET) Reference Lidar Intercomparison campaign 2009 (EARLI 09) (Freudenthaler et al., 2010) took place in Leipzig, Germany. The goal of this campaign was to assure the quality of the lidar measurements of five EARLINET reference systems. In the frame of this intercomparison campaign several commercially available lidars and ceilometers were placed aside the EARLINET lidars to study their ability to determine aerosol profiles. Among them was a Jenoptik ceilometer of type CHM15k-X. This is an improved instrument type allowing measurements closer to the ground. The specifications of the two ceilometer types are given in Sect. 2. These measurements were used for the CLIC study as well. The lidar used for the comparison was again IfTs' lidar Polly ${ }^{X T}$ (Althausen et al., 2009). Three weeks of data were available, but again, due to the weather conditions the number of useful measurement days was limited. The best day for the comparison was 25 May 2009. On this day three time periods from the ceilometer and lidar measurements were compared and the example of the night-time measurement will be shown in this paper.

In this contribution, we present the results from the ceilometer lidar comparison study including a comprehensive signal-to-noise ratio analysis. The latter allows the characterization of the signal performance of the ceilometer and thus determines how accurate aerosol layers can be detected by the Jenoptik CHM15k(-X) ceilometers. In the following section the instruments and their characteristics are presented. Thereafter the data retrieval methods are explained and the results from the CLIC study are shown and discussed.

\section{Instruments}

Polly ${ }^{\mathrm{XT}}$ is a fully automatic multi-wavelengths Raman lidar using a frequency doubled and tripled Nd:YAG laser. It detects the signals at the three elastically backscattered wavelengths at $355 \mathrm{~nm}, 532 \mathrm{~nm}$, and $1064 \mathrm{~nm}$, at two Raman shifted wavelengths at $387 \mathrm{~nm}$ and $607 \mathrm{~nm}$, and one depolarization signal at $355 \mathrm{~nm}$. The detection mode for all channels is photon counting plus one fast analog channel at $532 \mathrm{~nm}$. With this configuration, Polly ${ }^{\mathrm{XT}}$ is a mobile, state-of-the-art 3 backscatter +2 extinction +1 depolarization lidar. Simultaneously to the emitted light at $355 \mathrm{~nm}$ and $532 \mathrm{~nm}$ wavelengths Polly ${ }^{\mathrm{XT}}$ emits pulses at $1064 \mathrm{~nm}$ wavelength with $180 \mathrm{~mJ}$ at a repetition rate of $20 \mathrm{~Hz}$. This results in a laser power of $3.6 \mathrm{~W}$ at $1064 \mathrm{~nm}$. The primary mirror of the Newtonian telescope in the receiver has a diameter of $300 \mathrm{~mm}$. The vertical resolution of the data acquisition is $30 \mathrm{~m}$ and the data are typically stored with a temporal resolution of $30 \mathrm{~s}$.

The Jenoptik CHM15k(-X) is a one-wavelength nearinfrared laser ceilometer. Its optical design is based on separated lens telescopes of $100 \mathrm{~mm}$ diameter for the transmitter and receiver. A microchip Nd:YAG laser with a central wavelength of $1064.10 \mathrm{~nm}$ and a line width of $0.38 \mathrm{~nm}$ serves as the light source. The narrow line width and stable wavelength of the solid state laser facilitate an excellent background light suppression. The pulse energy of the laser is $8.4 \mu \mathrm{J}$ at $5-7 \mathrm{kHz}$ resulting in a laser power of about $50 \mathrm{~mW}$. The avalanche photo diode (APD) is used in photon counting mode and the signal in detected with a resolution of $15 \mathrm{~m}$. Within the DWD network the data are stored with a temporal resolution of $15 \mathrm{~s}$ or $30 \mathrm{~s}$. The instrument type CHM15k (CHM) is the standard instrument with a complete overlap at about $1500 \mathrm{~m}$ and a measurement range of $15 \mathrm{~km}$. A new version of the instrument, the CHM15k-X (CHX) has a 4-times wider field-of-view and improved optics facilitating a complete overlap at $150 \mathrm{~m}$. Further details on the Jenoptik ceilometers are described by Flentje et al. (2010) and Frey et al. (2010).

In terms of expected signal-to-noise performance of the ceilometer the lower laser power, the smaller receiving optics, and the higher noise of the APD detection compared to that of the lidars photomultiplier must be taken into account. Thus, the signals received by the ceilometer are noisier than those of the lidar and the altitude range up to which aerosol can be detected is limited.

\section{Data evaluation}

The temporal development of the range corrected ceilometer signal is revealing the aerosol structures in a time-height section. Fig. 1 shows an example of a CHX measurement on 25 May 2009. On this day the ceilometer data were stored every $30 \mathrm{~s}$. This results in 2880 data profiles per day and allows to plot the range corrected signal in a proper temporal 


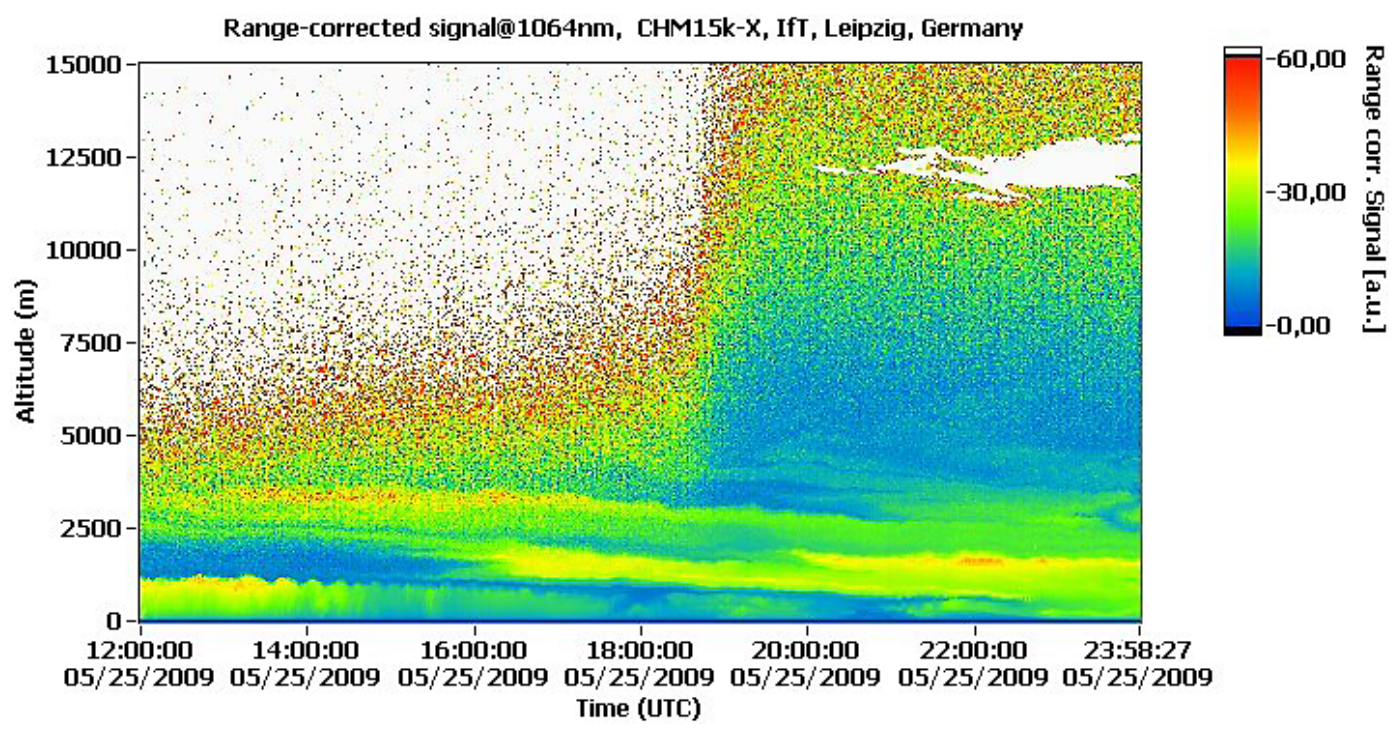

Fig. 1. Temporal development of the range corrected signal of the ceilometer Jenoptik CHM15k-X on 25 May 2009 from 12:00-23:59 UTC. The data have a temporal resolution of $30 \mathrm{~s}$ and a vertical resolution of $15 \mathrm{~m}$. Above the boundary layer (top height $\leq 1200 \mathrm{~m}$ ) a lofted Saharan dust layer is visible.

resolution. Together with the vertical resolution of $15 \mathrm{~m}$ quite detailed aerosol structures can be resolved in almost the entire lower troposphere down to a height of at least $150 \mathrm{~m}$ above the ground.

To retrieve vertical aerosol profiles the data from the ceilometers and the lidars elastic channel at $1064 \mathrm{~nm}$ are analyzed using the Fernald-Klett method (Fernald, 1984; Klett, 1981). With this method the particle backscatter coefficient is derived applying a backward iteration starting at a chosen reference height. The method requires independent information on the lidar ratio and on the reference value of the particle backscatter coefficient. During night-time the lidar data can be evaluated by the Raman method (Ansmann et al., 1992) using also the signal from the Nitrogen Raman channel at the $607 \mathrm{~nm}$. In contrast to the Fernald-Klett method here the extinction coefficient profile results directly from the measured Raman signal - without any prior assumptions. The retrieval of the particle backscatter coefficient profile, again, requires a reference value. Due to the wavelength dependence of the molecular scattering, the scattering efficiency for atmospheric particles at $1064 \mathrm{~nm}$ is much lower than that for the other lidar wavelengths. Therefore, the calibration of the raw data profile by a reference value chosen at an altitude where no particles but only molecules contribute to the measured signal is more difficult in the infrared spectrum. In case of ceilometer measurements the low signal and high noise level (see Sect. 5) above $5 \mathrm{~km}$ makes this calibration difficult. An example of different reference height choices and the resulting particle backscatter coefficient profile and aerosol optical depth (AOD) value is shown in Fig. 2. In this example the AOD calculated from the profiles using different reference heights differs significantly. Therefore, the correct magnitude of the particle backscatter coefficient profile can only be determined by a calibration with an independent measurement of the AOD.

The AOD is measured by the Aerosol Robotic Network (AERONET) sun photometer at IfT. This sun photometer measures the radiance in eight channels ranging from $340 \mathrm{~nm}$ to $1640 \mathrm{~nm}$. For the comparison with the lidar and the ceilometer observations AERONET level 2.0 data of the photometer channels were interpolated and the value at $1064 \mathrm{~nm}$ was used. During night-time no AOD measurements from a sun photometer are available. In this case the measurements from the evening before or the morning after have to be used and extrapolated to the ceilometer measurement time. If both measurements are available, the AOD can also be interpolated to achieve a reasonable value during night-time. The AOD from the ceilometer and lidar data are derived by integrating their extinction coefficient profiles. These extinction profiles are calculated from the respective particle backscatter coefficient profiles using the assumed lidar ratios that are valid for the respective aerosol layers. For simplification, in this study a constant lidar ratio of $55 \mathrm{sr}$ is assumed for both the lidar and the ceilometer that is valid for continental urban aerosol (Mattis et al., 2004), for Saharan dust (Müller et al. , 2007), and for volcanic ash plumes over Europe (Ansmann et al., 2010). The choice of a valid lidar ratio will always be a problem for the ceilometer aerosol retrieval since a measurement with only one backscattered wavelength does not allow for aerosol typing. But for the presented comparisons one should also keep in mind that the deviations of the real lidar ratio from the assumed one are not relevant since both data 


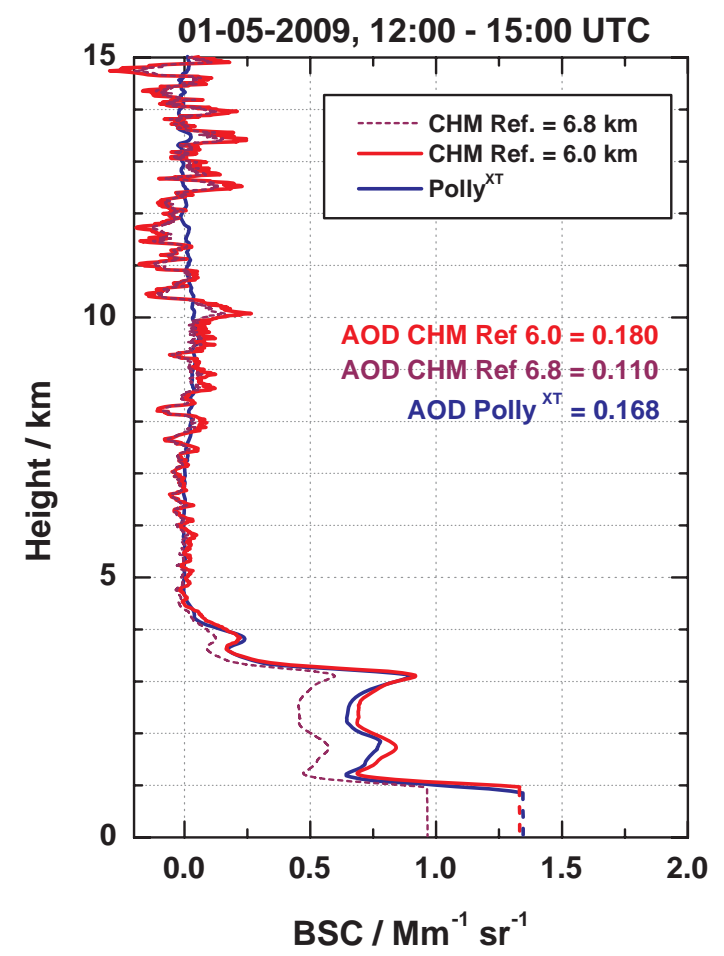

Fig. 2. Daytime particle backscatter coefficient profiles derived from the CHM ceilometer data from DWD in Holzhausen (in red) and lidar data (in blue). The mean AOD measurement from the AERONET sun photometer (level 2.0 data) for this time period interpolated to $1064 \mathrm{~nm}$ is 0.140 . Different results for particle backscatter coefficient profiles are obtained from the ceilometer data when varying the reference height chosen in the retrieval. For instance choosing the reference height at $6.8 \mathrm{~km}$ results in the particle backscatter coefficient profile in dashed purple and a calculated AOD of the 0.110 , which is too low. The reference value for the backscatter coefficient is $10^{-12} \mathrm{Mm}^{-1} \mathrm{sr}^{-1}$ in both cases.

sets are treated equally. To calculate the resulting AOD from the lidars and ceilometers extinction profiles in the overlap affected ranges, the extinction values at the height range with incomplete overlap below $1 \mathrm{~km}$ were extrapolated and set to the extinction value at $1 \mathrm{~km}$ height. The extrapolation invokes indeed a certain error which can be estimated to about $20 \%$ in the cases with a high aerosol layer top of about 4$5 \mathrm{~km}$ height, as presented in this paper. In other cases when the boundary layer top is lower or even inside the overlap region the error is increasing proportionally.

The vertical smoothing of all lidar and ceilometer profiles was done by a sliding polynomial filter which preserves the characteristic structure of the profiles. The same averaging length of $330 \mathrm{~m}$ was chosen for both instruments.

\section{Ceilometer lidar comparison}

Two representative cases of the CLIC study are shown and discussed in this paper. The first case is a daytime measurement from the DWD ceilometer network that shows that the background light leads to much noisier signals and reduces the maximum height for the retrieval of the particle backscatter coefficient profile. The other case is a night-time measurement during EARLI09 with lower background noiselevel which allows to identify the aerosol structures easier than during daytime.

\subsection{Daytime case}

Figure 2 shows an example of daytime profiles measured on 1 May 2009 from 12:00-15:00 UTC. The three-hour mean particle backscatter coefficient profile shown in red was derived from the measurement of the CHM type ceilometer placed at the DWD regional center. In blue the corresponding particle backscatter profile from Polly ${ }^{\mathrm{XT}}$ at the $1064 \mathrm{~nm}$ channel (Fernald-Klett solution) is plotted. The overall comparison of both profiles shows good agreement in the observed aerosol structures and a noisier profile of the ceilometer measurements at higher altitudes. Both instruments observed the boundary layer top at about $1 \mathrm{~km}$ height and a pronounced aerosol layer above the boundary layer reaching up to about $4.5 \mathrm{~km}$. Above this height the noise in the ceilometer signal is increasing with altitude. In contrast, the less noisy lidar profile is still resolving a weak aerosol layer at the height range from 8 to $12 \mathrm{~km}$. The particles observed at those altitudes may origin either from long-range transport of ashes from volcano eruptions earlier that year in Alaska or may be Saharan dust particles as well. FLEXPART (Stohl, 1998) calculations (not shown) at these heights indeed indicate a contribution of volcanic ashes from the Alaskan volcano outbreaks during winter and spring 2009. The presence of Saharan dust is less likely since neither the FLEXPART calculations nor the DREAM dust forecasts (www.bsc.es) indicate any dust over Leipzig.

To quantify the differences in the profiles, the AOD was calculated from the derived extinction profiles as described in Sect. 3. On 1 May 2009 the AOD derived from the ceilometer profile is 0.180 and the one from the lidar profile was calculated to 0.168 . The independent measurement of the AOD by IfTs sun photometer interpolated to $1064 \mathrm{~nm}$ over the same time period yields a value of 0.140 . These are differences in the order of $20 \%$. They can be explained by a slightly wrong lidar ratio, by the distance between the measurement sites, as well as by the extrapolation of the extinction profile to the ground with a constant value. Differences in this range can be expected considering the different measurement sites. However, the shape of the particle backscatter profiles from both instruments compare quite well. 


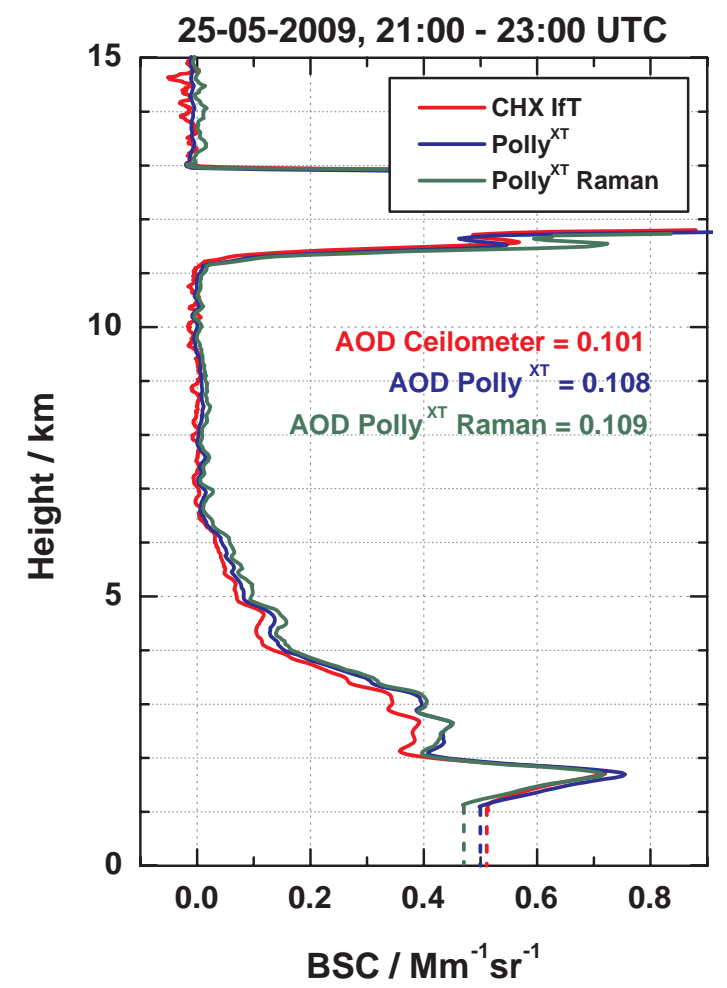

Fig. 3. Particle backscatter coefficient profiles derived from CHX ceilometer data at IfT (in red), lidar data (in blue), and Raman lidar data (in green). The AOD measured by the AERONET sun photometer during the last sun hour in the evening is 0.117 . The AOD from the lidar and ceilometer profiles is calculated up to $10 \mathrm{~km}$.

\subsection{Night-time case}

Figure 3 shows a night-time measurement taken during EARLI 09 on 25 May 2009 from 21:00-23:00 UTC. During night-time also the Raman channels of Polly ${ }^{\mathrm{XT}}$ can be used. The particle backscatter coefficient profile at $1064 \mathrm{~nm}$ was calculated from the ratio of the signals measured at $1064 \mathrm{~nm}$ and the ones measured at the $607 \mathrm{~nm}$ Raman channel. The resulting backscatter coefficient profile is shown in green and compares very well with Polly ${ }^{\mathrm{XT}}$ s elastic backscatter coefficient profile at $1064 \mathrm{~nm}$ derived using the Fernald-Klett method. The corresponding particle backscatter profile derived from the ceilometer data is shown in red. To verify the correctness of the absolute values of the particle backscatter coefficients at all three profiles the occurrence of a cirrus cloud between 11 and $13 \mathrm{~km}$ can be used.

Inside the cirrus cloud the backscatter coefficient is independent of the wavelength of the measured signal. Therefore, at these heights the backscattered signal at $1064 \mathrm{~nm}$ must have the same value as at the two other lidar wavelengths of $532 \mathrm{~nm}$ and $355 \mathrm{~nm}$ (not shown). With this knowledge the reference value can be set to a common value for the three lidar channels so that the backscatter coefficient has the same value for all signals at the three lidar wavelengths inside the cloud. Below the cloud the backscatter coefficient profile at each wavelength is again different from the others. This approach is a further proof for the correctness of the lidars backscatter coefficient calculated at $1064 \mathrm{~nm}$. In the case of the night-time measurement on 25 May 2009 the reference value was $8 \mathrm{Mm}^{-1} \mathrm{sr}^{-1}$ (not shown) inside the cloud at the reference height of $12 \mathrm{~km}$. For the data retrieval of the Polly ${ }^{\mathrm{XT}} \mathrm{s}$ signals this adjustment was done for both the particle backscatter coefficient profiles from the elastic wavelength and the Raman particle backscatter coefficient profile.

Regarding the aerosol structures in the profiles measured by both the ceilometer and the lidar the boundary layer top is detected at almost $2 \mathrm{~km}$ height. Another aerosol layer above the boundary layer is detected up to $6.5 \mathrm{~km}$ height. On this day a Saharan dust outbreak was observed over Europe. This was indicated by the corresponding DREAM forecasts (www.bsc.es). The dust layer was present over Leipzig during the whole night and its structure is well resolved by both the lidar and the ceilometer profiles. However, the particle backscatter coefficient profile calculated from the ceilometer is a bit lower than the lidar profiles, especially between $2 \mathrm{~km}$ and $4 \mathrm{~km}$ height. This results in a slightly lower calculated AOD of the ceilometer of 0.101 . The AOD calculated from the elastic lidar profile is 0.108 and compares very well to the values of 0.109 calculated from the Raman profile. The differences compared to the ceilometers' AOD result from the noisier ceilometer signal which makes the calibration of the ceilometer signal more difficult. However, the shape of the profiles is clearly in good agreement. The AOD measured by the sun photometer during the last hour before sunset when no cirrus was present was 0.115 . These are small differences that definitely remain inside the measurement errors. Another example of a night-time case is discussed in Flentje et al. (2010). Note also, that the increase of noise with altitude in the ceilometer particle backscatter coefficient profile appears to be less during night-time compared to the daytime particle backscatter coefficient profile. A more detailed analysis of the signal noise follows in the next section.

\section{Signal-to-noise ratio}

For the characterization of the ceilometers ability to determine aerosol layers at the different altitude levels quantitatively, the signal-to-noise ratio (SNR) has to be calculated. The SNR of a lidar or ceilometer signal is defined as the ratio of incoming signal to the amount of interfering noise.

The total detected signal $P_{\text {tot }}$ consists of the backscattered signal $P_{\text {sig }}$ plus the background signal $P_{\mathrm{bg}}$ :

$P_{\text {tot }}=P_{\text {sig }}+P_{\text {bg }}$

and

$P_{\text {sig }}=P_{\mathrm{tot}}-P_{\mathrm{bg}}$. 


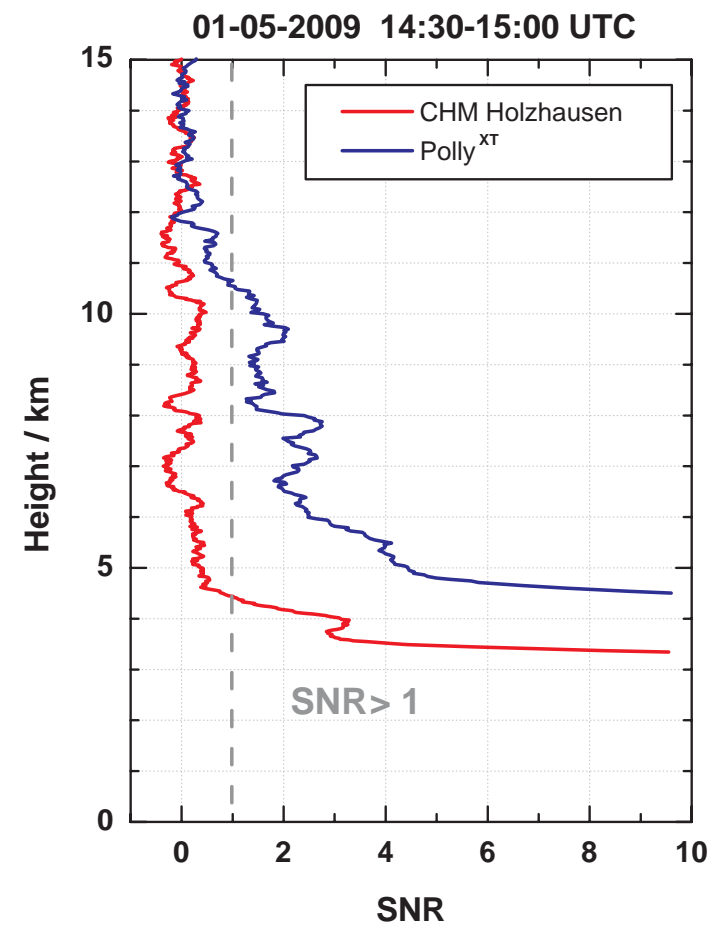

Fig. 4. SNR of 30 min mean CHM ceilometer and lidar signals on 1 May 2009 during daytime.

The background signal $P_{\mathrm{bg}}$ is calculated starting from the uppermost rangebin down to a height where the lidar or ceilometer signal $P_{\text {sig }}$ is still assumed to be negligible. The lidar or ceilometer signal $P_{\text {sig }}$ is then obtained by subtracting the background signal from the total signal $P_{\text {tot }}$.

Taking Gauß' error propagation law for the calculation of the signal noise $\Delta P_{\text {sig }}$ into account, we get:

$$
\Delta P_{\text {sig }}=\sqrt{\Delta P_{\mathrm{tot}}^{2}+\Delta P_{\mathrm{bg}}^{2}} \text {. }
$$

Since the detection mode of both the ceilometer and the lidar is photon counting their signal noise follows the Poisson statistics. The error of a counting rate is equal to its squareroot and is essentially shot-noise. Hence, with Eq. (3) it follows:

$\Delta P_{\text {sig }}=\sqrt{P_{\text {tot }}+P_{\mathrm{bg}}}=\sqrt{P_{\text {sig }}+2 P_{\text {bg }}}$.

Finally, the SNR can be expressed as:

$\mathrm{SNR}=\frac{P_{\mathrm{sig}}}{\sqrt{P_{\mathrm{sig}}+2 P_{\mathrm{bg}}}}$.

In the following the SNR of the presented measurements are discussed. A SNR higher than 1 is chosen here as a threshold for the signal to be analyzable since in this case the contribution from the signal is higher than the one from the noise.

During daytime (Fig. 4) the SNR of the ceilometer is higher than 1 up to about $4 \mathrm{~km}$ height. At this height, the

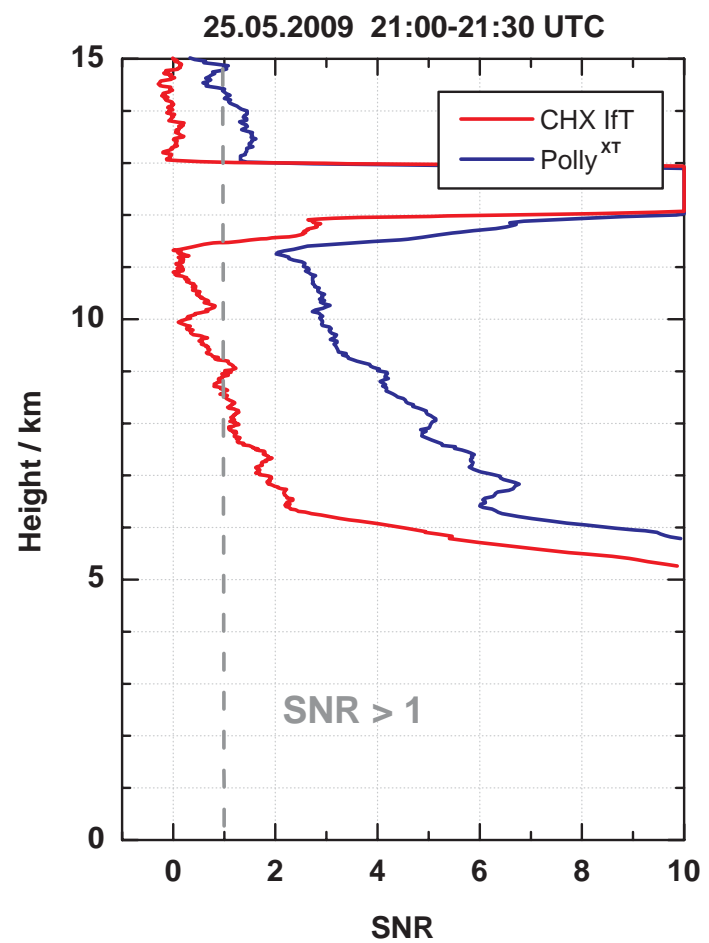

Fig. 5. SNR of 30 min mean CHX ceilometer and lidar signals on 25 May 2009 during night-time.

top of the main aerosol layer is reached. Above the aerosol layers the SNR is decreasing rapidly below 1. For comparison, the SNR for the Polly ${ }^{\mathrm{XT}}$ signal is shown, too. Due to the higher laser power and receiver efficiency it decreases below 1 above $12 \mathrm{~km}$ height. This means also that - in contrast to the ceilometer - Polly ${ }^{\mathrm{XT}}$ is able to measure the weak backscatter signal at $1064 \mathrm{~nm}$ from atmospheric molecules. During daytime the ceilometer signal is too noisy and is only capable to measure the signal backscattered from particles.

During night-time the altitude where the SNR of the ceilometer signal is decreasing below 1 is depending on the aerosol load and is mostly around $5 \mathrm{~km}$. In cases of high aerosol load in mid altitudes - as during a Saharan dust event over Europe - the SNR can also be above 1 at higher altitudes. The example of the night-time measurement from EARLI 09 is shown in Fig. 5. Here, the SNR is greater than 2 up to $6.5 \mathrm{~km}$, which is the dust layer top. Above this height the SNR decreases slowly and stays above $1 \mathrm{up} 8.5 \mathrm{~km}$, even for a $30 \mathrm{~min}$ mean profile. In the range of the cirrus cloud where the signal gets rapidly higher the SNR is increasing above 1. The signals from Polly ${ }^{X T}$ are above 1 up to the cirrus cloud and stay around 1 even above. Thus, although the first impression from the particle backscatter coefficient profiles during night-time (Fig. 3) implied a better SNR at higher altitudes, the SNR calculation shows the limits for the quantitative aerosol data evaluation from the ceilometer signals. 
To retrieve the backscatter coefficient profiles an aerosol free layer is needed where the reference value for the backscatter coefficient can be set. This means that the ceilometer should also be able to measure the molecular signal and not only noise when no aerosol is present at higher altitudes. Whether it is possible to detect the molecular signal can be determined by the signal-to-noise ratio. This ratio is depending on the received signal - which is of course higher for aerosol layers - but it is also depending on the signal background.

\section{Conclusions}

In this paper we show that the retrieval of particle backscatter coefficient profiles from ceilometer data is depending on the received signal compared to the noise and the decrease of the SNR with height. A reference value for the backscatter coefficient must be set in the retrieval algorithm. This can only be done if the ceilometer is able to measure any molecular signal and not only noise at higher altitudes. That this is a critical point has been demonstrated by presenting two representative examples for high and a low background signals. From the SNR study we can conclude that the ceilometer is able to detect aerosol layers in the boundary layer and up to about $4 \mathrm{~km}$ height during daytime. During night-time when background noise is low aerosol layers can be detected even up to higher altitudes. However, the SNR is depending on the presence of aerosol layers and decreases rapidly if the aerosol content declines. In the case of the Saharan dust event over Europe on 25 May 2009, the dust was observed at high altitudes also with the ceilometer. In this case the SNR was greater than 1 up to $8.5 \mathrm{~km}$ when averaging over half an hour. However, although the particle backscatter coefficient profiles from both instruments compare well in aerosol structures, the correct values of the particle backscatter coefficients can only be determined from ceilometer data when integrating the derived profiles to AOD values and compare them to an independent measurement of the AOD, e.g. from a sun photometer. This calibration with the AOD is necessary for every individual profile.

Another uncertainty of deriving the backscatter coefficient profile from ceilometer data is the unknown lidar ratio that has to be assumed for the respective aerosol type. The choice of the right lidar ratio is indeed a problem and is affecting the ceilometer measurements as long as the instruments do stand alone. A network of ceilometers for the determination of the aerosol distribution over an area like Germany would need at least a few anchor stations with AOD measurements from sun photometers. At these stations also a lidar would be helpful to determine the correct lidar ratio and thus the correct particle backscatter coefficient. With the measurements from these anchor stations also a scaling of all ceilometer profiles of the network would be possible and thus contribute to the spatial aerosol monitoring over Germany or even Europe.
Acknowledgements. This study was supported by the German Meteorological Service (DWD). We would like to thank all reviewers for their helpful comments during the discussion of the manuscript.

Edited by: M. Wendisch

\section{References}

Althausen, D., Engelmann, R., Baars, H., Heese, B., Ansmann, A., Müller, D., and Komppula, M.: Portable Raman Lidar Polly XT for Automated Profiling of Aerosol Backscatter, Extinction, and Depolarization, J. Atmos. Ocean. Tech., 26, 2366-2378, 2009.

Ansmann, A., Wandinger, U., Riebesell, M., Weitkamp, C., and Michaelis, W.: Independent measurement of extinction and backscatter profiles in cirrus clouds by using a combined Raman elastic-backscatter lidar, Appl. Optics, 31, 7113-7131, 1992.

Ansmann, A., Tesche, M., Groß, S., Freudenthaler, V., Seifert, P., Hiebsch, A., Schmidt, J., Wandinger, U., Mattis, I., Müller, D., and Wiegner M.: The 16 April 2010 major volcanic ash plume over central Europe: EARLINET lidar and AERONET photometer observations at Leipzig and Munich, Germany, Geophys. Res. Lett., 37, L13810, doi:10.1029/2010GL043809, 2010.

Fernald, F. G.: Analysis of atmospheric lidar observations: some comments, Appl. Optics, 23, 652-653, 1984.

Flentje, H., Heese, B., Reichardt, J., and Thomas, W.: Aerosol profiling using the ceilometer network of the German Meteorological Service, Atmos. Meas. Tech. Discuss., 3, 3643-3673, doi:10.5194/amtd-3-3643-2010, 2010.

Freudenthaler, V., Gross, S., Engelmann, R., Mattis, I., Wandinger, U., Pappalardo, G., Amodeo, A., Giunta, A., D’Amico, G., Chaikovsky, A., Osipenko, F., Slesar, A., Nicolae, D., Belegante, L., Talianu, C., Serikov, I., Linne, H., Jansen, F., Wilson, K., de Graaf, M., Apituley, A., Trickl, T., Giehl, H., and Adam, M.: EARLI09 - direct intercomparison of eleven EARLINET lidar systems Proceedings of the 25th International Laser Radar Conference, 5-9 July 2010, St.-Petersburg, Russia, 891-894, 2010.

Frey, S., Poenitz, K., Teschke, G., and Wille, H.: Detection of aerosol layers with ceilometers and the recognition of the mixed layer depth, presented at the International Symposium for the Advancement of Boundary Layer Remote Sensing (ISARS), 2010.

Klett, J. D.: Stable analytical inversion solution for processing lidar returns, Appl. Optics, 20, 211-220, 1981.

Markowicz, K. M., Flatau, P. J., Kardas, A. E., Remiszewska Remiszewskaj, J., Stelmaszczyk, K., and Wöste, L.: Ceilometer Retrieval of the Boundary Layer Vertical Aerosol Extinction Structure, J. Atmos. Ocean. Tech., 25, 928-944, 2007.

Martucci, G., Milroy, C., and O' Dowd, C. D.: Detection of Cloud-Base Height Using Jenoptik CHM15K and Vaisala CL31 Ceilometers, J. Atmos. Ocean. Tech., 27, 305-318, 2010.

Mattis, I., Ansmann, A., Müller, D., Wandinger, U., and Althausen, D.: Multiyear aerosol observations with dual-wavelength Raman lidar in the framework of EARLINET, J. Geophys. Res., 109, D13203, doi:10.1029/2004JD004600, 2004.

McKendry, I. G., van der Kampa, D., Strawbridge, K. B., Christen, A., and Crawford, B.: Simultaneous observations of boundarylayer aerosol layers with CL31 ceilometer and 1064/532 nm lidar, Atmos. Environ., 43, 5847-5852, 2009. 
Müller, D., Ansmann, A., Mattis, I., Tesche, M., Wandinger, U., Althausen, D., and Pisani, G.: Aerosol-type-dependent lidar ratios observed with Raman lidar, J. Geophys. Res., 112, D16202, doi:10.1029/2006JD008292, 2007.

Stachlewska, I. S. and Markowicz, K. M.: On forward Klett's inversion of ceilometer signals, 25th ILRC International Laser Radar Conference, 5-9 July 2010, St. Petersburg, Russia, 2010.
Stohl, A., Hittenberger, M., and Wottowa, G.: Validation of the Lagrangian particle dispersion model FLEXPART against large scale tracer experiments, Appl. Optics, 32(24), 4245-4263, doi:1016/S1352-2310(98)00184-8,1998.

Sundström, A.-M., Nousiainen, T., and Petäjä, T.: On the Quantitative Low-Level Aerosol Measurements Using Ceilometer-Type Lidar, J. Atmos. Ocean. Tech., 26, 2340-2352, 2000. 